\title{
Management of inflammatory bowel disease in older persons: evolving paradigms
}

\author{
Saurabh Kedia ${ }^{1}$, Jimmy K. Limdi ${ }^{2}$, Vineet Ahuja ${ }^{1}$ \\ ${ }^{1}$ Department of Gastroenterology and Human Nutrition, All India Institute of Medical Sciences, New Delhi, India, ${ }^{2}$ Salford \& Pennine Clinical \\ Research Unit, The Pennine Acute Hospitals NHS Trust, Manchester, UK
}

The incidence and prevalence of inflammatory bowel disease (IBD) is increasing, and considering the aging population, this number is set to increase further in the future. The clinical features and natural history of elderly-onset IBD have many similarities with those of IBD in younger patients, but with significant differences including a broader differential diagnosis. The relative lack of data specific to elderly patients with IBD, often stemming from their typical exclusion from clinical trials, has made clinical decision-making somewhat challenging. Treatment decisions in elderly patients with IBD must take into account agespecific concerns such as comorbidities, locomotor and cognitive function, and polypharmacy, to set realistic treatment targets in order to enable personalized treatment and minimize harm. Notwithstanding paucity of clinical data, recent studies have provided valuable insights, which, taken together with information gleaned from previous studies, can broaden our understanding of IBD. These insights may contribute to the development of paradigms for the holistic and, when possible, evidencebased management of this potentially vulnerable population and are the focus of this review. (Intest Res 2018;16:194-208)

Key Words: Crohn disease; Colitis, ulcerative; Aging; Therapeutics; Outcomes

\section{INTRODUCTION}

Inflammatory bowel diseases (IBD), comprising CD and UC, are characterized by a relapsing and remitting course, the incidence and prevalence of which are increasing worldwide. ${ }^{1}$ Population aging, meanwhile, is a global phenomenon, with individuals aged 65 years and over representing the fastest growing age group. ${ }^{2}$ In the West, the proportion of elderly persons (aged 65 and over) has increased in the last decade from $12.3 \%$ (USA) and $17.3 \%$ (Sweden) to $14.8 \%$ and $19.9 \%$, respectively. ${ }^{3}$ Likewise, Asia has also seen an increase in elderly persons in the last decade, from $19.8 \%$ to $26.3 \%$ in Japan, from $9.2 \%$ to $13.1 \%$ in South Korea, and in India from

Received October 5, 2017. Revised November 11, 2017.

Accepted November 14, 2017. Published online March 6, 2018

Correspondence to Vineet Ahuja, Department of Gastroenterology and

Human Nutrition, All India Institute of Medical Sciences, Room No. 3111,

Third Floor, Teaching Block, New Delhi 110029, India. Tel: +91-11-26593300,

Fax:+91-11-26588663, E-mail: vineet.aiims@gmail.com
$4.8 \%$ to $5.6 \%$ over the last 10 years. ${ }^{3}$ Thus, population aging, coupled with the increasing global incidence of IBD and its negligible impact on mortality, will contribute to the increase in the number of older persons diagnosed with IBD in the future. Clinicians will consequently face 2 distinct paradigms: individuals diagnosed at a younger age who attain an elderly age, and those first diagnosed at or after the age of 60 years. ${ }^{2}$ The challenges posed by clinical comorbidities, polypharmacy with the risk of potential drug interactions, the likely mismatch between chronological and biological age, and a myriad of social issues underpin the complexities involved in managing elderly persons with IBD. Despite the paucity of clinical data limiting evidence-based decisions (largely from the exclusion of individuals aged 65 years and over in clinical trials), there has been resurgent interest and research in recent years, contributing to our understanding of IBD pathophysiology in elderly individuals. This review will discuss the epidemiology, clinical features, and subtle nuances in the management of these patients with an emphasis on elderly-

(c) Copyright 2018. Korean Association for the Study of Intestinal Diseases. All rights reserved.

This is an Open Access article distributed under the terms of the Creative Commons Attribution Non-Commercial License (http://creativecommons.org/licenses/by-nc/4.0)

which permits unrestricted non-commercial use, distribution, and reproduction in any medium, provided the original work is properly cited. 
onset IBD. The widely accepted criteria of age 60 and over is used define older-onset (or "elderly"-onset) IBD. ${ }^{2}$

\section{EFFECTS OF AGING}

\section{Immune Effects and Pharmacokinetics}

Aging may be associated with a relative immunosenescence resulting from a decline in both innate and adaptive immunity. ${ }^{4}$ This may result from a decrease in hematopoietic stem cells (decreased bone marrow production), naïve $\mathrm{T}$ cells (thymic atrophy), and reduced ability of peripheral lymphoid cells to undergo clonal expansion or regeneration. Consequently, there is an attenuation of cell-mediated immune response, phagocytic activity, and monocyte and macrophage function. ${ }^{4}$ Other changes associated with aging include altered gastrointestinal motility, reduction in gastric $\mathrm{pH}$, increased intestinal permeability, and changes in the gut microbiota with a reduction in bacterial diversity, including increased populations of Bacteriodes and reduced numbers of Firmicutes and Bifidobacteria. ${ }^{4,5}$ Aging may also be associated with a state of chronic low-grade inflammation from pro-inflammatory cytokine release from peripheral blood mononuclear cells. ${ }^{5}$

Many physiological changes that accompany aging may affect pharmacokinetics and drug metabolism. ${ }^{6}$ These in- clude an increase in body fat, decline in body water volume, plasma volume, and lean muscle mass. ${ }^{6}$ Additionally, there is a reduction in the hepatic and splanchnic blood flow, glomerular filtration rate, levels of plasma proteins, and their binding capacities. These age-related changes may alter free and protein bound drug levels, altering the half-life and clearance of various medications. As a result, elderly patients are at greater risk of steroid toxicity because of diabetes, hypertension, infections, glaucoma, cataract, dyslipidemia, osteoporosis, and fractures. ${ }^{6}$ Pharmacokinetics of anti-tumor necrosis factor $\alpha$ (TNF- $\alpha$ ) agents are also affected by increased baseline concentrations of TNF (increased production), decreased TNF catabolism by the reticuloendothelial system and reduced serum albumin. ${ }^{7}$ The implications of immunosenescence on the etiology of IBD in elderly patients requires further study, but emphasizes the potential for altered pharmacokinetics and adverse effects in elderly patients.

\section{EPIDEMIOLOGY}

The proportion of patients with elderly-onset IBD varies from $3 \%$ to $21 \%$ for $\mathrm{CD}^{8-11}$ and $7 \%$ to $29 \%$ for UC (Table 1). ${ }^{8-16}$ The majority (65\%) are diagnosed during the 6 th decade, $25 \%$ during the 7 th decade, and $10 \%$ during the 8 th decade. $^{17}$

Table 1. Proportion of Elderly-Onset (>60 Years) Patients among All Patients with IBD

\begin{tabular}{|c|c|c|c|c|}
\hline \multirow{2}{*}{ Author (year) } & \multirow{2}{*}{ Country } & \multirow{2}{*}{ No. of patients } & \multicolumn{2}{|c|}{ Age (yr) } \\
\hline & & & $\leq 60$ & $>60$ \\
\hline \multicolumn{5}{|l|}{$C D$} \\
\hline Hwang et al. $(2017)^{9}$ & South Korea & 1,224 & 1,194 (97) & $30(3)$ \\
\hline Saygili et al. $(2017)^{12}$ & Turkey & 1,187 & $1,092(97)$ & $95(9)$ \\
\hline Nguyen et al. $(2017)^{10}$ & Canada & 8,985 & $8,260(92)$ & $725(8)^{a}$ \\
\hline Hou et al. (2016) & USA & 724 & $632(87)$ & $92(13)^{a}$ \\
\hline Jeuring et al. (2016) ${ }^{8}$ & The Netherlands & 1,162 & $1,026(88)$ & $136(12)$ \\
\hline \multicolumn{5}{|l|}{ UC } \\
\hline Song et al. $(2018)^{13}$ & South Korea & 3,060 & 2,834 (93) & $226(7)$ \\
\hline Nguyen et al. $(2017)^{10}$ & Canada & 12,233 & $10,484(86)$ & $1,749(14)^{a}$ \\
\hline Lin et al. $(2016)^{14}$ & Taiwan & 536 & 459 (86) & $77(14)$ \\
\hline Hou et al. $(2016)^{11}$ & USA & 876 & 722 (82) & $159(18)^{a}$ \\
\hline Jeuring et al. $(2016)^{8}$ & The Netherlands & 1,661 & $1,288(78)$ & $373(22)$ \\
\hline Fries et al. $(2017)^{15}$ & Italy & 1,091 & $808(74)$ & $283(26)$ \\
\hline Shi et al. $(2016)^{16}$ & Hong Kong & 1,225 & $1,068(87)$ & $157(13)$ \\
\hline
\end{tabular}

Values are presented as number (\%).

${ }^{a}$ Age $>65$ years. 
The incidence of elderly-onset IBD is increasing at an unprecedented rate globally, with significant heterogeneity in data derived from urban populations, large populationbased registries, and the developing world. ${ }^{1}$ Thus, the incidence of UC and CD varies from 1.1/100,000 to 16.5/100,000 and from $0 / 100,000$ to $18.9 / 100,000$, respectively. ${ }^{18}$ In a large population-based study (French population-based registry [EPIMAD]) from Northern France, the incidence of UC and CD was 3.1/10,000 and 2.6/100,000 inhabitants respectively. ${ }^{17}$ In general, the incidence rates of UC are higher than those of $\mathrm{CD}$ in the elderly. In a study from Hungary, the incidence of UC in the elderly increased from 1.09/100,000 (1977-1981) to $10.8 / 100,000(2002-2007) .{ }^{19}$ Similarly, the incidence of $\mathrm{CD}$ in the elderly increased from being virtually unknown (until the 1990s) to $3.04 / 100,000(2002-2007) .{ }^{19} \mathrm{In}$ another study, elderly-onset IBD incidence rates increased from $11.71 / 100,000$ persons in 1991 to $23.66 / 100,000$ persons in 2010. ${ }^{8}$ IBD disease burden is increasing in India and in other rapidly developing countries; in 2010, India had the second highest disease burden of IBD in the world after the United State. $^{20}$
In the recently published Asia-Pacific Crohn's and Colitis Epidemiology study, across 21 centers in 9 countries from the Asia-Pacific, the incidence of UC and CD in the elderly population (over 60 years of age) was $\sim 0.8 / 100,000$ population and $\sim 0.3 / 100,000$, respectively. ${ }^{21}$ In another study from South Korea, the incidence of elderly-onset UC increased from $3.9 \%(1997-1999)$ to $9.7 \%(2008-2014)(P<0.001){ }^{13}$ Finally, in a study from Hong Kong, the proportion of newly diagnosed elderly-onset UC increased significantly during the past 2 decades (from $3.0 \%$ before 1990 to $21.6 \%$ after 2010). ${ }^{16}$ The parallelism between improved sanitization and IBD emergence is striking from data on IBD incidence in the developing world and may help to unmask likely clues from the "exposome" in the etiology of IBD. ${ }^{2}$

\section{DIAGNOSTIC CONSIDERATIONS}

The clinical presentations of elderly- and younger-onset IBD have many similarities, as well as important differences. ${ }^{2}$ There may be a considerable delay in the diagnosis in elderly persons for a multitude of reasons ranging from the wide-

Table 2. Differential Diagnosis of IBD

\begin{tabular}{|c|c|c|}
\hline Disease & Clinical characteristics & Additional features \\
\hline Infectious colitis & $\begin{array}{l}\text { Bloody diarrhea } \\
\text { Urgency/tenesmus } \\
\text { History of fever } \\
\text { Acute onset }\end{array}$ & $\begin{array}{l}\text { Possible pseudo-membranes with Clostridium difficile colitis } \\
\text { Stool cultures usually diagnostic } \\
\text { Rapid resolution with appropriate antibiotic therapy }\end{array}$ \\
\hline Radiation colitis & $\begin{array}{l}\text { Diarrhea with bleeding } \\
\text { Abdominal pain/cramps } \\
\text { Proctitis (urgency and tenesmus) } \\
\text { History of pelvic radiation }\end{array}$ & Telangiectasia on endoscopy and fibrosis seen at histology \\
\hline NSAIDs enteropathy & $\begin{array}{l}\text { Diarrhea } \\
\text { Recurrent pain abdomen } \\
\text { Obstruction } \\
\text { Iron deficiency anemia } \\
\text { History of NSAIDs }\end{array}$ & $\begin{array}{l}\text { Lesions isolated } \\
\text { Any part of intestine may be affected } \\
\text { Diaphragm like small bowel strictures } \\
\text { Exacerbate existing CD or UC }\end{array}$ \\
\hline Ischemic colitis & $\begin{array}{l}\text { Sudden onset pain abdomen } \\
\text { Diarrhea with bleeding }\end{array}$ & $\begin{array}{l}\text { Segmental distribution of colitis } \\
\text { Typically sigmoid/left sided colitis } \\
\text { Rectum spared and abrupt cutoff with non-involved segment }\end{array}$ \\
\hline $\begin{array}{l}\text { Segmental colitis associated } \\
\text { with diverticulitis }\end{array}$ & $\begin{array}{l}\text { Diarrhea with bleeding } \\
\text { Abdominal pain } \\
\text { History of associated comorbidities } \\
\text { such as diabetes, hypertension, CAD }\end{array}$ & $\begin{array}{l}\text { Segmental peridiverticular distribution } \\
\text { Rectum and proximal colon spared }\end{array}$ \\
\hline Solitary rectal ulcer syndrome & $\begin{array}{l}\text { Bleeding per rectum } \\
\text { Urgency } \\
\text { History of chronic constipation, } \\
\text { straining, digital evacuation }\end{array}$ & $\begin{array}{l}\text { Mucosal thickening } \\
\text { Crypt architectural distortion } \\
\text { Collagen deposition and smooth muscle in lamina propria }\end{array}$ \\
\hline
\end{tabular}

$C A D$, coronary artery disease. 
ranging differential diagnosis and the potential for misdiagnosis to disinclination in seeking medical advice and indeed even access to specialist healthcare. ${ }^{2}$ Misdiagnosis may occur in up to $60 \%$ of elderly patients with IBD as compared to $15 \%$ of younger patients, with a delay in diagnosis of up to 6 years. The differential diagnosis of IBD in the elderly includes infectious colitis, ischemic bowel disease, segmental diverticulitis, NSAID enteropathy, malignancy, microscopic colitis, radiation enteritis, and solitary rectal ulcer syndrome (Table 2). ${ }^{2}$ The increasing incidence of Clostridium difficile infection (CDI) is of concern, in elderly patients affected by a virulent strain, with more serious consequences such as prolonged hospitalization, increased risk of surgery and mortality. ${ }^{2}$ Colonic disease, corticosteroid, and immunosuppressive therapy are risk factors for $\mathrm{CDI}^{2,22}$ This underpins the importance of CDI testing in all hospitalized patients with IBD, especially in those experiencing a flare and those not responding to therapy. ${ }^{2}$

A family history of IBD is less common with elderly-onset IBD. ${ }^{89,11,14,16}$ The prevalence of extraintestinal manifestations is also lower, varying from $0 \%$ to $7 \%$ (Table 3 ). ${ }^{8-11,14-16,23-25}$ The frequency of thromboembolic complications, however, is much higher in elderly patients, possibly due to hypercoagulable states, relative immobility, and dehydration associated with illness.
There is a higher prevalence of comorbidities in patients with elderly-onset IBD than in young patients. The number of comorbidities increases with age. ${ }^{26}$ Recent studies from Korea $^{13}$ and Hong Kong ${ }^{16}$ have shown that the proportion of patients with hypertension, diabetes mellitus, cerebrovascular disease, heart disease, chronic obstructive pulmonary disease, and extracolonic malignancy was significantly higher in the elderly-onset UC group.

\section{DISEASE CHARACTERISTICS}

\section{Clinical Features}

Across all studies, males appear to be affected (56\%-62\%) more often with elderly-onset UC than females (38\%-44\%), and this sex-associated distribution appears to be consistent with that in overall UC population across all studies (Table 3). $8,10,11,14-16$

The frequency of abdominal pain, weight loss, and fever is lower in elderly-onset disease than in younger-onset disease. ${ }^{2,14,17}$ The first presentation of UC, however, may be more severe in elderly-onset UC. ${ }^{2}$

In a study from Taiwan, patients with elderly-onset UC were more likely to have severe activity at initial diagnosis (32.4\%) than patients with younger-onset UC $(16.8 \%) .{ }^{14}$ Sim-

Table 3. Disease Characteristics of Patients with Elderly Onset IBD

\begin{tabular}{|c|c|c|c|c|c|}
\hline Author (year) & Country & No. of patients & Female sex $(\%)$ & Family history (\%) & EIM (\%) \\
\hline \multicolumn{6}{|l|}{$C D$} \\
\hline Hwang et al. (2017) ${ }^{9}$ & South Korea & 1,224 & 67 & 0 & - \\
\hline Hou et al. (2016) & USA & 92 & - & 8 & - \\
\hline Nguyen et al. $(2017)^{10}$ & Canada & 725 & 62 & - & - \\
\hline Cheddani et al. $(2016)^{23}$ & France & 370 & 62 & - & 5 \\
\hline Jeuring et al. $(2016)^{8}$ & The Netherlands & 136 & 63 & - & - \\
\hline Saad et al. $(2016)^{24}$ & USA & 30 & 47 & - & 6.3 \\
\hline $\begin{array}{l}\text { Yamamoto-Furusho and } \\
\text { Sarmiento-Aguilar }(2015)^{25}\end{array}$ & Mexico & 27 & 63 & 0 & 34 \\
\hline \multicolumn{6}{|l|}{ UC } \\
\hline Hou et al. (2016) & USA & 159 & - & 4 & - \\
\hline Nguyen et al. $(2017)^{10}$ & Canada & 1,749 & 55 & - & - \\
\hline Cheddani et al. $(2016)^{23}$ & France & 474 & 38 & - & - \\
\hline Fries et al. $(2017)^{15}$ & Italy & 283 & 44 & - & 7 \\
\hline Lin et al. $(2016)^{14}$ & Taiwan & 77 & 40 & 0 & 0 \\
\hline Jeuring et al. $(2016)^{8}$ & The Netherlands & 373 & 44 & - & - \\
\hline Shi et al. $(2016)^{16}$ & Hong Kong & 157 & 39 & 1.7 & - \\
\hline
\end{tabular}

EIM, extraintestinal manifestations. 
ilarly, in a Dutch study, more patients with elderly-onset UC were hospitalized at the time of diagnosis (5.7\% vs. $2.9 \%){ }^{8}$

In elderly patients with $\mathrm{CD}$, most studies have reported a higher female to male ratio, with the proportion of females varying from $47 \%$ to $67 \%$ (Table 3). ${ }^{8-10,12,24,25}$ Elderly-onset patients with $\mathrm{CD}$ tend to have more rectal bleeding but less abdominal pain, fever, or weight loss at presentation. ${ }^{2}$

A recent study from the United States, however, reported that disease behavior was similar in younger- and elderlyonset IBD, although immunomodulatory therapy was less frequently used for elderly-onset IBD. ${ }^{27}$

\section{Disease Extent and Location}

\section{1) Ulcerative Colitis}

In a meta-analysis by Ananthakrishnan et al., ${ }^{28}$ left sided UC disease was the most common (45\%; 95\% CI, $40 \%-$ $52 \%)$, followed by pancolitis (31\%), and proctitis (22\%). Subsequent studies have shown similar trends, with left sided UC being the most common (range, $34 \%-56 \%$ ), followed by pancolitis (range, 14\%-38\%), and proctitis (range, $13 \%-45 \%))^{8,11,13-16}$

Data regarding proximal extension in these patients is contradictory. In a study from South Korea, proximal extension was less common (22.9\%) elderly-onset UC than in the younger-onset UC (32.0\%), ${ }^{13}$ whereas in a French population-based cohort study, $84 \%$ of patients with elderly-onset UC remained stable with no proximal extension. ${ }^{17}$

\section{2) Crohn's Disease}

In a recent meta-analysis, the most common disease location for elderly-onset CD was colonic (44\%; 95\% CI, $36 \%-52 \%$ ), followed by ileal (32\%), and ileo-colonic disease (26\%) ${ }^{28}$ Upper gastrointestinal involvement was uncommon (7\%). Inflammatory disease was the most common behavior (68\%; 95\% CI, 61\%-74\%), followed by stricturing (24\%), and penetrating disease (8\%). Perianal involvement was relatively uncommon (12\%). In subsequent studies, colonic location was most common (range, 30\%-65\%) followed by ileal (range, 10\%-50\%), and ileo-colonic (range, 10\%-38\%), with inflammatory behavior being most common (68\%-96\%), followed by stricturing and penetrating disease. . $9,11,12,24,25^{-1}$

\section{Disease Course and Natural History}

\section{1) Ulcerative Colitis}

Elderly-onset UC appears to follow an indolent disease course. In a recent meta-analysis, overall rates of surgery, immunomodulator use, and biologic use in patients with UC were $9 \%, 17 \%$, and $4 \%$, respectively. ${ }^{28}$ Patients with elderlyonset UC were less likely to receive immunomodulators (OR, 0.60; 95\% CI, 0.45-0.79) or biologic therapies (OR, 0.41; $95 \% \mathrm{CI}, 0.27-0.62)^{27}$ and were more likely to undergo surgery (OR, 1.36; 95\% CI, 1.18-1.57; $P<0.001$ ). ${ }^{28}$ Higher rates of surgery indicate that the disease course is probably not as mild or reflect a preference for surgery in patients because of fear of adverse events with immunosuppressants. Similarly, in the EPIMAD registry, ${ }^{17}$ the lower proportion of patients with extensive colitis at diagnosis, but the higher rate of early colectomy and no difference in the use of medications, suggests a similar disease course. In a recent study from South Korea, the proportion of patients with extensive colitis (54.4\%) requiring systemic steroid (53.5\%) and immunosuppressants (26.6\%) was significantly higher among elderly-onset UC. ${ }^{13}$ Similar findings were also reported by a recent study from Hong Kong. ${ }^{16}$

\section{2) Crohn's Disease}

In the meta-analysis by Ananthakrishnan et al., ${ }^{28}$ overall rates of surgery, immunomodulator use, and biologic use in elderly-onset CD patients were $32 \%, 32 \%$, and $15 \%$, respectively. Patients with elderly-onset disease were significantly less likely to receive immunomodulators or biologics than patients with younger-onset disease, but the need for surgery was similar for both types of patients with no differences at the 1-and 5-year follow-up. The rates of disease progression in patients with elderly-onset $C D$ have been lower than those in patients with non-elderly-onset CD, as suggested in a recent Dutch study ${ }^{8}$ and in the EPIMAD registry where the disease behavior remained stable in $91 \%$ of elderly patients after a median follow-up period of 6 years. ${ }^{17}$ Elderly-onset CD patients are at a higher risk of surgery at diagnosis, although the long-term rate of surgery remains similar between elderly-onset and young-onset CD patients. Unlike UC, disease course, progression, hospitalization, and surgery in elderly-onset CD has remained consistent over the years.

Another recent study found that pure colonic location (L2) was more frequent among patients aged $>70$ years at diagnosis than among patients aged $>60$ years at diagnosis ( $73 \%$ vs. $57 \%$ ), with inflammatory behavior being most common. ${ }^{29}$ There was no significant difference in either group with respect to treatment with aminosalicylates (5-ASAs), oral corticosteroids, and anti-TNF therapies. Risk of surgery was similar in both groups. The lower risk of disease extension or severity in elderly-onset CD patients treated with 
5-ASAs has led to the provocative, but plausible, suggestion that colonic CD of elderly onset may have a UC phenotype or even that 5-ASAs may have a possible role in this subgroup of patients. ${ }^{17,29,30}$

Elderly patients with IBD appear to have a higher risk of hospitalization. Ananthakrishnan and Binion ${ }^{31}$ reported that $25 \%$ of all IBD-related hospital admissions in the USA were in patients aged over 65 years. These patients were likely to be more malnourished, anemic and hypovolemic with higher transfusion requirements, and with longer postoperative hospital stays especially after surgery.

Venous thromboembolic complications are more common in patients with elderly-onset IBD and stem from inflammatory disease activity and associated hypercoagulability, reduced physical activity, and the potential for dehydration. ${ }^{2}$

\section{IBD TREATMENT IN THE ELDERLY}

\section{Medical Treatment}

The most commonly used medications in elderly patients with IBD are 5-ASAs, which are prescribed in 30\% to $90 \%$ of patients with $\mathrm{CD}^{8,9,12,24,25}$ and $60 \%$ to $90 \%$ of patients with $\mathrm{UC}^{8,13,14,16}$ respectively. Although the reasons for this remain unclear, the predominance of colonic disease and potentially less aggressive disease course in both UC and CD could account for differences in prescription. Up to a third of elderly
IBD patients receive steroid therapy, ${ }^{32}$ with the cumulative probability of steroid use at 10 years being $47 \%$ and $40 \%$ in elderly patients with CD and UC, respectively. ${ }^{17}$ In the meta-analysis by Ananthakrishnan et al., ${ }^{28}$ the overall rates of immunomodulator and biologic use were $32 \%$ and $15 \%$, respectively, in elderly patients with CD and $17 \%$ and $4 \%$, respectively, in elderly patients with UC, and this was significantly lower than that in patients with the young-onset IBD. More recent literature also concurs with these findings, with overall rates of thiopurine (range, 4\%-57\%), anti-TNF (range, $0 \%-15 \%$ ), and steroid use (range, $15 \%-56 \%$ ) matching that of the recent meta-analysis (Table 4) $)^{8,9,11-44,16,23-25}$ The reduced use of immunomodulators and anti-TNF is consistent across the literature, which may be driven in part by physician hesitancy for fear of adverse effects and also from a relatively more indolent disease course not requiring immunomodulation.

\section{1) Aminosalicylates}

5-ASAs are foundational therapy for the induction and maintenance of remission in UC. ${ }^{2,33}$ Despite their controversial role in $\mathrm{CD}$, they are commonly prescribed in elderly patients with CD. In the EPIMAD study, 5-ASAs were prescribed in $75 \%$ of patients with similar clinical phenotype in CD and UC. ${ }^{17}$ Amongst the CD patients, 68\% received 5-ASAs at 1 year, $77 \%$ at 5 years, and $80 \%$ at 10 years of follow-up. Over $50 \%$ of the UC patients were on 5-ASA mono-

Table 4. Treatment Details of Patients with Elderly-Onset IBD

\begin{tabular}{|c|c|c|c|c|c|c|c|}
\hline Author (year) & Country & No. of patients & 5-ASA & Thiopurine & Anti-TNF- $\alpha$ & Steroids & Surgery \\
\hline \multicolumn{8}{|l|}{$C D$} \\
\hline Hwang et al. (2017) ${ }^{9}$ & South Korea & 30 & 95 & 33 & 15 & - & - \\
\hline Saygili et al. $(2017)^{12}$ & Turkey & 95 & 90 & 57 & 2 & - & 22 \\
\hline Jeuring et al. $(2016)^{8}$ & The Netherlands & 136 & - & 23 & 6.9 & 39 & 33 \\
\hline Saad et al. $(2016)^{24}$ & USA & 30 & 90 & 66 & 55 & 90 & 28 \\
\hline $\begin{array}{l}\text { Yamamoto-Furusho and } \\
\text { Sarmiento-Aguilar }(2015)^{25}\end{array}$ & Mexico & 27 & 30 & 22 & 0 & 15 & 73 \\
\hline \multicolumn{8}{|l|}{ UC } \\
\hline Song et al. $(2018)^{13}$ & South Korea & 226 & - & 18 & 10 & 52 & 9.7 \\
\hline Lin et al. $(2016)^{14}$ & Taiwan & 77 & 90 & 4 & 0 & - & - \\
\hline Jeuring et al. $(2016)^{8}$ & The Netherlands & 373 & - & - & - & 46 & 8 \\
\hline Shi et al. $(2016)^{16}$ & Hong Kong & 157 & - & 27 & 0 & 53 & 5 \\
\hline \multicolumn{8}{|l|}{ IBD } \\
\hline Hou et al. (2016) & USA & 272 & 80 & 17 & 5 & 37 & - \\
\hline Cheddani et al. $(2016)^{23}$ & France & 844 & - & 14 & 4 & - & - \\
\hline
\end{tabular}

5-ASA, 5-aminosalicylic acid; TNF, tumor necrosis factor. 
therapy and did not require surgery. ${ }^{17}$ Between $88 \%$ and $90 \%$ of patients with colonic CD were receiving 5-ASAs with over two-thirds given maintenance therapy at maximal followup. ${ }^{17}$ The widespread use of 5-ASAs in patients with CD is in agreement with other population-based cohorts. ${ }^{19}$ This has led to a provocative suggestion that 5-ASAs may in fact have a role in elderly-onset $C D{ }^{30}$

The combination of oral and topical 5-ASAs is more effective than oral therapy alone. ${ }^{33}$ Complex dosing regimens and polypharmacy could negatively influence compliance and once-daily dosing regimens may be preferable..$^{33}$ Anorectal dysfunction in the elderly ranges between $10 \%$ to $25 \%$ in hospitalized patients and $4 \%$ in outpatients. ${ }^{34}$ This raises the issue of difficulties with the use of topical therapy arising from physical limitations with reduced retention of enema fluid in the presence of active inflammation. Reduction in the volume of the enema or substitution with a corticosteroid foam preparation may circumvent this problem. ${ }^{35}$

Although 5-ASAs are relatively safe, there have been rare reports of nephrotoxicity and interstitial nephritis, which appear idiosyncratic rather than age-related. ${ }^{36}$ Common side effects include nausea, vomiting, abdominal pain, headache, and rash. ${ }^{33}$ Paradoxical worsening of colitis can occur in less than $5 \%$ of patients, which improves after discontinuing the drug. ${ }^{37}$

The potential for drug interaction with other agents such as warfarin, increasing its anticoagulant activity, ${ }^{38}$ increased 6-thioguanine levels with potential for myelosuppression, ${ }^{39}$ and interaction with isoniazid should also be considered. ${ }^{36}$

\section{2) Corticosteroids}

Corticosteroids are the cornerstone of decisive induction of remission in UC patients with an inadequate response to 5-ASAs, in acute severe UC, and to induce clinical remission in $\mathrm{CD}^{33,40}$

They are associated with a higher risk of adverse events. In a Canadian study of 3,522 patients with elderly-onset IBD, the rate of serious infections (pneumonia, intestinal infections, $C$. difficile enterocolitis) was significantly higher in patients with IBD exposed to steroid use within the previous 6 months with the risk being highest in current steroid users (adjusted OR, 2.3; 95\% CI, 1.8-2.9). ${ }^{41}$ The Therapy, Resource, Evaluation, and Assessment Tool registry also reported a hazard ratio (HR) of 1.6 (95\% CI, 1.2-2.1) for serious infections associated with steroid use within 6 months and higher mortality related to corticosteroid exposure. ${ }^{42}$ Dose-related side effects have been reported in $40 \%$ of elderly patients with long-term corticosteroid use and osteoporosis in $16 \%$ of patients. ${ }^{43}$ Despite the sheer futility of prolonged steroid exposure with its inherent risks, elderly persons with IBD appear to be treated with corticosteroid therapy. Furthermore, the published literature to date demonstrates inadequacies in exit strategies once steroids are initiated. In a study of 393 elderly patients with IBD ( $>65$ years), corticosteroid usage had doubled from $35 \%$ (1991-2000) to $64 \%$ (2001-2010). ${ }^{44}$ Disappointingly, elderly-onset patients with IBD also received higher average prednisolone doses than younger patients $(8 \mathrm{mg} /$ day vs. $2.2 \mathrm{mg}$ /day respectively, $P<0.005)$ and over a third of elderly-onset IBD patients received steroids for over 6 months. ${ }^{44}$ A U.S. Medicare cohort study of over 8,500 patients with elderly-onset IBD found that $20 \%$ of patients receiving anti-TNF therapy had received corticosteroids for over 3 months, and 10\% for over 6 months. ${ }^{45}$ Additionally, $43 \%$ of elderly patients had received anti-TNF concomitantly with corticosteroids in multiple courses spanning over 3 months. ${ }^{45}$ It is likely that physician hesitancy in escalating to immunomodulatory therapy, even in "well-selected" patients, and the notion that corticosteroid therapy is "safer" may be driving this practice. These studies emphasize the importance of steroid stewardship with careful contingency planning.

Corticosteroids are associated with other serious morbidities such as altered mental state and depression, fluid retention, glaucoma, osteoporosis and fractures. ${ }^{46}$ In one study, osteoporotic-related fractures and osteonecrosis were noted in $15 \%$ of patients with elderly IBD ${ }^{47}$ The widespread prevalence of malabsorption and calcium and vitamin D deficiency in the elderly should prompt early and regular bone densitometry assessments. Bisphosphonates should be considered alongside vitamin D and calcium supplementation. $^{33,40}$

Steroids may reduce the activity of drugs such as phenytoin, phenobarbital, ephedrine, and rifampicin. Anticoagulant efficacy of warfarin may also be affected, and careful monitoring of coagulation parameters is recommended. ${ }^{2}$

Budesonide may be recommended for induction of remission in mild-to-moderate distal small bowel and rightsided colonic $\mathrm{CD}^{40} \mathrm{~A}$ novel formulation of budesonide in a multimatrix release formulation has recently been approved for use in mild-moderate extensive UC. The judicious use of these formulations as a bridge to conventional steroids may reduce unnecessary steroid exposure although the full impact of this intervention needs further and formal study.

\section{3) Immunomodulators}

Immunomodulators may be indicated in elderly patients 
demonstrating corticosteroid dependence. ${ }^{2,40}$ A network meta-analysis of nearly 40 randomized controlled trials in CD patients found that neither thiopurines nor methotrexate improved the odds of achieving remission over placebo but a significant difference was noted with respect to maintenance of remission. ${ }^{48}$ The relative paucity of clinical data on the use of thiopurines in elderly patients is reflected in the disparate practices with respect to their use. ${ }^{49}$

In a retrospective study of 393 patients with IBD aged over 65 years, one-third were on long-term corticosteroids (over 6 months) with only $6 \%$ on thiopurines and $1 \%$ on methotrexate. ${ }^{44}$ While it is plausible that differential prescribing patterns for immunomodulatory therapy may be driven by physician hesitancy, immunomodulators are associated with a higher risk of opportunistic infections and other serious adverse effects such as a higher risk of malignancy, as discussed below. ${ }^{50-54}$ Taken together, the data suggest sufficient cause for concern with the use of thiopurines in elderly persons and when possible suitable alternatives should be preferred. ${ }^{2}$ Although methotrexate has not been studied specifically in elderly patients, no adverse reports have emerged from their use in elderly persons with rheumatoid arthritis and psoriasis and they have not been associated with malignancy. Methotrexate has been used in CD but consensus opinion currently does not favor its use as monotherapy in UC. ${ }^{2,33,40}$ The role of methotrexate in elderly patients with IBD needs to be studied further.

\section{4) Anti-TNF Agents}

The role of anti-TNF therapy in the decisive induction and maintenance of remission in moderate to severely active IBD has been established through pivotal trials for nearly 2 decades. ${ }^{2,33,40}$ Data supporting their efficacy in elderly patients are limited and conflicting, with some studies showing similar results in elderly- and younger-onset IBD ${ }^{55,56}$ and others suggesting lower efficacy. ${ }^{57,58}$ A U.S. study found the rates of partial/complete response in the elderly to be significantly lower than in younger patients with IBD (61\% vs. 83\%) ${ }^{57}$ In a nested case control study from Leuven in which 239 patients were treated with anti-TNF, the clinical response at 10 weeks was significantly lower in elderly-onset IBD than in youngeronset IBD patients (68\% vs. $89 \%$ ), although the long-term efficacy ( $>6$ months) was similar between the 2 groups ( $79 \%$ vs. 83\%) ${ }^{55}$ In another study of 95 patients with elderly-onset IBD treated with anti-TNF between 2000 and 2009, 65\% of patients with CD and 59\% with UC achieved clinical remission as opposed to $59 \%$ and $57 \%$ in a control group of under 65 years. ${ }^{56}$ Discontinuation rates in elderly patients at 12 months have also been higher, with concomitant use of thiopurines being the only significant predictor of early discontinuation, potentially driven by infection risk from bimodal immunosuppression. ${ }^{57}$

Data on safety of anti-TNF therapy consistently report increased rates of adverse events in elderly patients. Early experience from the Mayo Clinic demonstrated that 3 of 4 deaths from infliximab therapy occurred in elderly patients, although the independent contribution of age was unclear in these patients who have a longer disease course, and more severe disease and multiple comorbidities. ${ }^{58}$ In another long-term cohort study of 734 patients with IBD treated with infliximab, age was the only predictor of mortality in patients on anti-TNF therapy. ${ }^{59}$ In a multicenter retrospective casecontrol study, the rate of infections ( $11.5 \%$ vs. $2.6 \%$ vs. $0.5 \%$, $P<0.001)$ and mortality ( $10.5 \%$ vs. $1.1 \%$ vs. $2.1 \%, P<0.001)$ was higher in elderly patients ( $>65$ years) on anti-TNF than in younger patients ( $<65$ years) on anti-TNF vs. elderly patients not on anti-TNF. ${ }^{56}$ The Massachusetts study also reported a higher risk of adverse events in elderly anti-TNF users, which led to $70 \%$ of elderly patients discontinuing therapy after 2 years ${ }^{57}$ In the study from Leuven, elderly patients on antiTNF therapy had a higher risk of any adverse event, and on multivariate analysis, age $\geq 65$ was the only risk factor for a serious adverse event on anti-TNF. ${ }^{55}$

\section{5) Anti-integrins}

Anti-integrins are a novel addition to the expanding therapeutic armamentarium for IBD. In the post hoc analysis in GEMINI trials, the efficacy and safety profiles of vedolizumab were similar across all age groups $(<35,35$ to $<55$, and $\geq 55$ years $){ }^{60}$ Vedolizumab-treated patients aged $\geq 55$ had the lowest incidence of serious infections ( 0.9 per 100 person-years) and adverse events leading to hospitalization (14.8 per 100 person-years). There were no differences in hematological events, malignancy, or deaths with regard to age. In a recent study of 29 elderly IBD patients (10 UC, 19 CD), the efficacy (48\% clinical response at 14 weeks, $55 \%$ at 52 weeks), and safety (13.8\% adverse events) of vedolizumab were similar to the results of GEMINI trials. ${ }^{61}$ Head-to-head comparisons between vedolizumab and other biological agents discussed above are now needed to position it within the current treatment algorithms of active IBD. The gut specificity and safety profile of vedolizumab may be appealing especially where monotherapy is desirable. ${ }^{2}$ 


\section{Polypharmacy and Its Impact}

The potential for clinical comorbidities, locomotor, and cognitive disturbances that influence the choice, response, and outcomes of IBD therapy must be considered when planning treatment, its objectives, and desired outcomes in elderly IBD patients. Comorbidities may affect therapeutic choices, for example, patients with diabetes and hypertension may not be ideal candidates for steroids. ${ }^{62}$ Anti-TNF therapy is contraindicated in patients with congestive heart failure (NYHA class III/IV), and patients with a history of recent malignancy $(<2$ years) may not be suitable candidates for thiopurines where the risk of lymphoproliferative disorders is also higher. ${ }^{50,63}$ With multiple comorbidity comes the risk of polypharmacy (use of multiple medications), including prescribed and over-the-counter medications. It has been reported that $>30 \%$ of elderly patients are taking more than 5 prescription medications concurrently in the United States, ${ }^{64}$ which may increase the risk of adverse events and drug interactions that could affect the efficacy and safety of IBD medications. Elderly IBD patients on average may be on 9 to 10 medications, with the potential for drug interactions in one-third of these patients. ${ }^{65}$ This highlights the need for scrupulous attention to the medical history, concomitant medication use, and suitable optimization of IBD specific therapy. ${ }^{2}$

\section{Surgery}

Approximately $25 \%$ of all intestinal surgeries are performed in patients over 55 years of age. Failure of medical therapy remains the most likely indication for surgery. ${ }^{19,66}$

Surgical rates in patients with elderly-onset UC are higher than those in patients with non-elderly-onset UC, as reported in the meta-analysis by Ananthakrishnan et al. ${ }^{28}(\mathrm{OR}$, 1.36; 95\% CI, 1.18-1.57, $P<0.001)$ and in recent studies from both western (5-year cumulative probability: $10.4 \%$ vs. $5.4 \%$ ) and eastern ( 0.24 vs. $0.18, P=0.24$; 10 -year cumulative probability: $6.1 \%$ vs. $3.7 \%$ ) parts of the globe. ${ }^{14,15}$ A Canadian study also reported a higher 5 -year cumulative risk of surgery for elderly-onset UC ( $13.6 \%$ vs. $10.3 \%$ vs. $11.2 \%$ ) than for UC in younger/ middle aged patients. ${ }^{10}$ The adjusted HR for surgery in the elderly with UC was 1.34 (95\% CI, 1.16-1.55) and 1.25 (95\% CI, 1.08-1.44) compared with that in young adults and middle-age adults, respectively. However, in a recent Dutch study, the 5 -year (7\% vs. $5.8 \%$ ) and 10 -year ( $8 \%$ vs. $7.8 \%$ ) cumulative colectomy rates were similar in patients with elderly- and young-onset UC. ${ }^{8}$
Elderly age appears to be a predictor of early surgery among patients with CD as reported in a recent Dutch study (surgery rates at diagnosis: $14.1 \%$ vs. $7.1 \%, P<0.05$ ). However, the overall surgery rates are similar in young and elderly $C D$ patients as reported by Ananthakrishnan et al. ${ }^{28}$ (OR, 0.70; 95\% CI, 0.40-1.22; pooled 5-year surgery rate: OR, 0.89; $95 \%$ CI, 0.61-1.29), by a recent Dutch study (5- and 10-year cumulative surgery rates: $27.1 \%$ vs. $39.2 \%$ and $34.2 \%$ vs. $32.9 \%$, respectively), ${ }^{8}$ and by a study from Canada (5- and 10- year cumulative surgery rates: $24.1 \%$ vs. $22.6 \%$ and $31.0 \%$ vs. $26.7 \%$, respectively). ${ }^{10}$

\section{1) Outcomes of Surgery and Complications}

Total colectomy with permanent ileostomy (TPCI) is the most commonly performed procedure in elderly-onset UC (77.3\%), whereas total colectomy with ileal pouch-anal anastomosis (IPAA) is the preferred procedure in younger patients, which may be largely attributable to concerns about the disturbance of sphincter function and fecal incontinence after surgery in elderly patients $(79.9 \%)^{2,13,67}$

A systemic review by Shung et al. ${ }^{68}$ reported surgeryassociated complications observed in elderly IBD patients. Postoperative complications after surgery decreased from the years 1960-1984 to 1994-1999 and elderly age was not a predictor of adverse outcome. ${ }^{69}$ There was no significant difference in morbidity or 30-day mortality between TPCI versus IPAA procedures. ${ }^{70}$ The incidence of postoperative cardiac and pulmonary complications was higher in the elderly than in younger patients. ${ }^{66}$ Functional outcomes after IPAA are generally similar to those of younger patients. ${ }^{68}$ In a recent study, which used the American College of Surgeons National Surgical Quality Improvement Program dataset, ${ }^{71}$ the odds of 30-day postoperative mortality in elderly patients was 4.4 -fold greater in UC ( $6.1 \%$ vs. $0.7 \%$ ) and 11.7 -fold greater in CD ( $4.2 \%$ vs. $0.3 \%$ ) than those in younger patients with IBD. The rates of postoperative complications (34.5\% vs. $21.3 \%, P<0.001)$ including cardiac dysfunction $(2.5 \%$ vs. $0.3 \%, P<0.001)$, renal dysfunction $(2.7 \%$ vs. $0.9 \%, P<0.001)$, neurologic complications ( $0.8 \%$ vs. $0.2 \%, P<0.001)$, ventilator dependence (7.2\% vs. $1.3 \%, P<0.001)$, and infection $(21 \%$ vs. $14.7 \%, P<0.001)$ were significantly higher in the elderly patients than in younger patients. In a study of 32,833 patients with UC, elective colectomy was associated with better survival than medical therapy (HR, $0.70 ; 95 \% \mathrm{CI}, 0.54-0.90)$, and on subgroup analysis, this effect remained significant only in the age group $>50$ years (HR, 0.60; 95\% CI, 0.45-0.79). ${ }^{72}$

IPAA is the surgical procedure of choice in UC if the patient has good anal sphincter function with no history of 
fecal incontinence. ${ }^{22,33,73}$ Pouch function deteriorates with increasing age with fecal incontinence, an effect that may be more pronounced in the elderly. ${ }^{2,74}$ Despite this, patients report a high level of satisfaction with IPAA, with $89 \%$ of elderly UC patients stating that they would opt to undergo the procedure again and $96 \%$ willing to recommend it to others. ${ }^{75}$

Taken together, these observations emphasize the importance of careful patient selection, assessment of local motor, cognitive, and anal sphincter function in planning and timing optimal surgical procedures for best possible outcomes.

\section{MORTALITY}

The all-cause and UC-related mortality rates have been reported to be higher in patients with elderly-onset UC..$^{10,13,16}$ Higher disease-related mortality has also been reported in elderly-onset CD with solid malignancies, accounting for $22.9 \%$ and $26.4 \%$ of deaths, in UC and CD respectively. ${ }^{10}$

\section{MALIGNANCY}

Two important paradigms apply to IBD-related cancer risk in elderly patients, the risk of colorectal cancer (CRC) as a result of long standing mucosal inflammation and the risk of extra-intestinal cancers (e.g., lymphoproliferative disorders and skin cancers), which are related to immunomodulator and biologic treatment for IBD-related inflammation. ${ }^{2}$ The risk of CRC in IBD increases with increasing disease duration, positive family history of IBD, primary sclerosing cholangitis, and prolonged and persistent mucosal inflammation. ${ }^{76}$ The influence of age on CRC risk in IBD remains controversial. In previous studies, earlier age of onset was associated with early development of CRC. ${ }^{77}$ Shaukat et al. ${ }^{78}$ recently reported that patients transitioning to an elderly age with CD or UC had an OR of $1.93(P<0.001)$ and 1.45 $(P=0.01)$, respectively, for developing CRC. However, in the EPIMAD registry, among 844 patients with IBD with a median follow-up of 6 years, there was no increased risk of CRC in the elderly IBD population as compared to the general population. ${ }^{23}$ Studies from the United States ${ }^{11}$ and Italy ${ }^{15}$ also did not find any difference in the CRC risk between elderly and adults with IBD.

Screening and surveillance for dysplasia in elderly IBD patients also remains controversial. Studies have reported higher rates of post-procedure hospitalization and perforation with CRC screening and therefore screening and surveillance strategies should consider associated comorbidities. $^{79}$ The overriding principle governing CRC screening, is that it should only be performed in patients deemed fit to undergo colectomy should dysplasia be found, and a life expectancy such that they would be expected to benefit. ${ }^{33,80}$

The risk of lymphoproliferative disorders increases with age. In 3 meta-analyses comprising 6 (3,891 patients), 18 (35,126 patients), and 26 (8,905 patients) studies, the standard incidence ratio of lymphoma in patients with IBD treated with thiopurines was $>4$, and there was a progressive increase in this risk with age. ${ }^{81-83}$ Additionally, the Cancers et Surrisque Associé aux Maladies Inflammatoires Intestinales En France (CESAME) group identified elderly age and longer duration of IBD as the main risk factors for developing lymphoma. ${ }^{50}$ In a German study, the risk of lymphoma and skin cancers was associated with over 4 years of thiopurine exposure as compared to anti-TNF exposure, and the risk was highest in patients aged $>50$ years. ${ }^{84}$ Another population-based study from Eastern Europe did not find any relation between thiopurine exposure and lymphoma. ${ }^{85}$ However, follow-up was relatively short, and therefore a modestly increased risk of lymphoma with thiopurines could not be ruled out. In a case control study from the United States, increasing age, male sex, and immunosuppressive, but not anti-TNF exposure, were associated with an increased risk of lymphoma ${ }^{86}$ In the only study that has addressed this issue specifically in the elderly (Cheddani et al.,. ${ }^{23}$ data from EPIMAD), there was an increased risk of lymphoproliferative and myeloproliferative disorders in the elderly with IBD, and this risk was higher in patients with CD; however, this risk was not related to thiopurine exposure.

The CESAME study showed that thiopurine use was associated with an increased risk nonmelanoma skin cancer and urinary tract malignancies in addition to lymphoma, and demonstrated that these were associated with a lower risk of CRC, which could be explained by a better control of inflammation.$^{50}$ Long et al. ${ }^{87}$ also identified thiopurine exposure as a risk factor for nonmelanoma skin cancer. Hou et al. ${ }^{11}$ showed that the frequency of extracolonic cancer (nonmelanoma skin and prostate) was higher in the elderly than in adults. However, another population-based study from the United Kingdom did not find any increase in the overall risk of cancer in IBD patients on azathioprine, although lymphoma risk increased in this study.

\section{VACCINATIONS}

Elderly patients may be at an increased risk of infections for myriad reasons, such as clinical comorbidities, exposure to immunosuppressive medications (e.g., corticosteroids, 
immunomodulators, and biological therapies), and susceptibility conferred by immunosenescence itself. ${ }^{89}$ Steroid exposure and advancing age are recognized risk factors for CDI. ${ }^{90}$ International consensus guidelines recommend vaccinating patients on or very likely to commence meaningful immunosuppressive therapy for control of their IBD. ${ }^{89,91}$ Patients are considered immunosuppressed if they are on $20 \mathrm{mg}$ or more of prednisolone (or equivalent), subjected to on-going treatment with effective doses of thiopurines, methotrexate, biological therapies, or have had these agents discontinued within 3 months. ${ }^{89,91}$ Vaccination recommendations are similar across age groups, although patients over 60 years of age may have sub-optimal serological responses. ${ }^{89,91,92}$ Recommendations include the inactivated influenza vaccine annually, pneumococcal vaccine given periodically (5-yearly), an initial dose followed by the vaccination in those over 65 years after 5 years regardless of immunosuppression status, the hepatitis B series of vaccinations (if not immune), and the meningococcal vaccine (for those living in enclosed spaces such as dormitories and those who have undergone splenectomy). Live vaccines must be avoided in immunosuppressed patients and these include the intranasal influenza and oral typhoid vaccines, and the BCG, varicella, yellow fever, anthrax, and measles-mumps-rubella vaccines. If required, live vaccines should be given at least 3 weeks before commencing meaningful immunosuppressive therapy or 3 months after stopping such therapy. Inactivated vaccines may be given at any time from the diagnosis of IBD, but ideally at the earliest available opportunity after diagnosis.

\section{CONCLUSIONS}

Rapid strides in the understanding of the immunopathogenesis of IBD, bolder definitions for disease control, and emphasis on mucosal healing over symptom control alone have significantly influenced our therapeutic paradigms with earlier introduction of immunomodulatory and anti-TNF therapy in well-selected patients. However, could one size ever fit all? Any enthusiasm that seeks to translate modern treatment paradigms universally to elderly patients should be tempered by an appreciation of the potential differences between "chronological" and "biological" age. Thus, a frail patient at any age with comorbid illness and limited mobility would be at a higher risk from complications of a medical or surgical intervention as opposed to a much older but "fit" individual. Age-specific concerns such as comorbidity, locomotor, and cognitive function, polypharmacy, and its potential consequences must all be considered carefully. There is an urgent need for further research into the biology of aging and its implications for IBD, as also for testing treatment paradigms in elderly persons. Until then, clinicians must make personalized decisions weighing on available evidence for the holistic, and when possible evidence-based, optimal management of elderly patients with IBD.

\section{FINANCIAL SUPPORT}

The authors received no financial support for the research, authorship, and/or publication of this article.

\section{CONFLICT OF INTEREST}

No potential conflict of interest relevant to this article was reported.

\section{AUTHOR CONTRIBUTION}

S.K., collection of data and drafting the manuscript; J.K.L., review and editing the manuscript; and V.A., review and editing the manuscript. All authors approved the final version of the manuscript.

\section{REFERENCES}

1. Molodecky NA, Soon IS, Rabi DM, et al. Increasing incidence and prevalence of the inflammatory bowel diseases with time, based on systematic review. Gastroenterology 2012;142:46-54.

2. Sturm A, Maaser C, Mendall M, et al. European Crohn's and Colitis Organisation topical review on IBD in the elderly. J Crohns Colitis 2017;11:263-273.

3. He W, Goodkind D. Kowal P. An aging world: 2015. Suitland: United States Census Bureau, 2016.

4. Cambier J. Immunosenescence: a problem of lymphopoiesis, homeostasis, microenvironment, and signaling. Immunol Rev 2005;205:5-6.

5. Franceschi C, Capri M, Monti D, et al. Inflammaging and anti-inflammaging: a systemic perspective on aging and longevity emerged from studies in humans. Mech Ageing Dev 2007;128:92-105.

6. Klotz U. Pharmacokinetics and drug metabolism in the elderly. Drug Metab Rev 2009;41:67-76.

7. Gupta S, Chiplunkar S, Kim C, Yel L, Gollapudi S. Effect of age on molecular signaling of TNF-alpha-induced apoptosis in human lymphocytes. Mech Ageing Dev 2003;124:503-509. 
8. Jeuring SF, van den Heuvel TR, Zeegers MP, et al. Epidemiology and long-term outcome of inflammatory bowel disease diagnosed at elderly age-an increasing distinct entity? Inflamm Bowel Dis 2016;22:1425-1434.

9. Hwang SW, Kim JH, Im JP, et al. Influence of age at diagnosis on the clinical characteristics of Crohn's disease in Korea: results from the CONNECT study. J Gastroenterol Hepatol 2017;32:1716-1722.

10. Nguyen GC, Bernstein CN, Benchimol EI. Risk of surgery and mortality in elderly-onset inflammatory bowel disease: a population-based cohort study. Inflamm Bowel Dis 2017;23:218-223.

11. Hou JK, Feagins LA, Waljee AK. Characteristics and behavior of elderly-onset inflammatory bowel disease: a multi-center US study. Inflamm Bowel Dis 2016;22:2200-2205.

12. Saygili F, Saygili SM, Tenlik I, et al. Crohn's disease in the elderly: clinical presentation and manifestations from a tertiary referral center in Turkey. North Clin Istanb 2017;3:183-186.

13. Song EM, Lee HS, Park SH, et al. Clinical characteristics and long-term prognosis of elderly-onset ulcerative colitis. J Gastroenterol Hepatol 2018;33:172-179.

14. Lin WC, Tung CC, Lin HH, et al. Elderly adults with late-onset ulcerative colitis tend to have atypical, milder initial clinical presentations but higher surgical rates and mortality: a Taiwan Society of Inflammatory Bowel Disease study. J Am Geriatr Soc 2016;64:e95-e97. doi: 10.1111/jgs.14427.

15. Fries W, Viola A, Manetti N, et al. Disease patterns in late-onset ulcerative colitis: results from the IG-IBD "AGED study". Dig Liver Dis 2017;49:17-23.

16. Shi HY, Chan FK, Leung WK, et al. Natural history of elderlyonset ulcerative colitis: results from a territory-wide inflammatory bowel disease registry. J Crohns Colitis 2016;10:176-185.

17. Charpentier C, Salleron J, Savoye G, et al. Natural history of elderly-onset inflammatory bowel disease: a population-based cohort study. Gut 2014;63:423-432.

18. Stepaniuk P, Bernstein CN, Targownik LE, Singh H. Characterization of inflammatory bowel disease in elderly patients: a review of epidemiology, current practices and outcomes of current management strategies. Can J Gastroenterol Hepatol 2015;29:327-333.

19. Lakatos PL, David G, Pandur T, et al. IBD in the elderly population: results from a population-based study in Western Hungary, 1977-2008. J Crohns Colitis 2011;5:5-13.

20. Singh P, Ananthakrishnan A, Ahuja V. Pivot to Asia: inflammatory bowel disease burden. Intest Res 2017;15:138-141.

21. Ng SC, Tang W, Ching JY, et al. Incidence and phenotype of inflammatory bowel disease based on results from the AsiaPacific Crohn's and colitis epidemiology study. Gastroenterology 2013;145:158-165.
22. Cohen SH, Gerding DN, Johnson S, et al. Clinical practice guidelines for Clostridium difficile infection in adults: 2010 update by the Society for Healthcare Epidemiology of America (SHEA) and the Infectious Diseases Society of America (IDSA). Infect Control Hosp Epidemiol 2010;31:431-455.

23. Cheddani H, Dauchet L, Fumery M, et al. Cancer in elderly onset inflammatory bowel disease: a population-based study. Am J Gastroenterol 2016;111:1428-1436.

24. Saad AM, Czul F, Sakuraba A, Rubin DT, Cohen RD. Age of diagnosis is associated with disease presentation and therapeutic complications in patients with Crohn's disease. Inflamm Bowel Dis 2016;22:1027-1031.

25. Yamamoto-Furusho JK, Sarmiento-Aguilar A. Mild clinical behaviour of Crohn disease in elderly patients in a Latin American country: a case-control study. Can J Gastroenterol Hepatol 2015;29:435-439.

26. Tinetti ME, Bogardus ST Jr, Agostini JV. Potential pitfalls of disease-specific guidelines for patients with multiple conditions. N Engl J Med 2004;351:2870-2874.

27. Barnes EL, Kochar B, Long MD, et al. Modifiable risk factors for hospital readmission among patients with inflammatory bowel disease in a nationwide database. Inflamm Bowel Dis 2017;23:875-881.

28. Ananthakrishnan AN, Shi HY, Tang W, et al. Systematic review and meta-analysis: phenotype and clinical outcomes of older-onset inflammatory bowel disease. J Crohns Colitis 2016;10:1224-1236.

29. Fumery M, Pariente B, Sarter H, et al. Natural history of Crohn's disease in elderly patients diagnosed over the age of 70 years: a population-based study. Inflamm Bowel Dis 2016;22:16981707.

30. Limdi JK. Aminosalicylates and elderly-onset colonic Crohn's disease-more than meets the eye? J Crohns Colitis 2017;11:1022.

31. Ananthakrishnan AN, Binion DG. Treatment of ulcerative colitis in the elderly. Dig Dis 2009;27:327-334.

32. Benchimol EI, Cook SF, Erichsen R, et al. International variation in medication prescription rates among elderly patients with inflammatory bowel disease. J Crohns Colitis 2013;7:878-889.

33. Magro F, Gionchetti P, Eliakim R, et al. Third European evidence-based consensus on diagnosis and management of ulcerative colitis. Part 1: definitions, diagnosis, extra-intestinal manifestations, pregnancy, cancer surveillance, surgery, and ileo-anal pouch disorders. J Crohns Colitis 2017;11:649-670.

34. Rao SS; American College of Gastroenterology Practice Parameters Committee. Diagnosis and management of fecal incontinence. Am J Gastroenterol 2004;99:1585-1604. 
35. Limdi JK. Rectal therapy in ulcerative colitis: science and sensitivity. Inflamm Bowel Dis 2016;22:E24-E25. doi: 10.1097/ MIB.0000000000000834.

36. Gisbert JP, González-Lama Y, Maté J. 5-Aminosalicylates and renal function in inflammatory bowel disease: a systematic review. Inflamm Bowel Dis 2007;13:629-638.

37. Kapur KC, Williams GT, Allison MC. Mesalazine induced exacerbation of ulcerative colitis. Gut 1995;37:838-839.

38. Wells PS, Holbrook AM, Crowther NR, Hirsh J. Interactions of warfarin with drugs and food. Ann Intern Med 1994;121:676683.

39. de Boer NK, Wong DR, Jharap B, et al. Dose-dependent influence of 5-aminosalicylates on thiopurine metabolism. Am J Gastroenterol 2007;102:2747-2753.

40. Gomollón F, Dignass A, Annese V, et al. 3rd European evidencebased consensus on the diagnosis and management of Crohn's disease 2016. Part 1: diagnosis and medical management. J Crohns Colitis 2017;11:3-25.

41. Brassard P, Bitton A, Suissa A, Sinyavskaya L, Patenaude V, Suissa S. Oral corticosteroids and the risk of serious infections in patients with elderly-onset inflammatory bowel diseases. Am J Gastroenterol 2014;109:1795-1802.

42. Lichtenstein GR, Feagan BG, Cohen RD, et al. Serious infection and mortality in patients with Crohn's disease: more than 5 years of follow-up in the TREAT" registry. Am J Gastroenterol 2012;107:1409-1422.

43. Thomas TP. The complications of systemic corticosteroid therapy in the elderly: a retrospective study. Gerontology 1984;30:6065.

44. Juneja M, Baidoo L, Schwartz MB, et al. Geriatric inflammatory bowel disease: phenotypic presentation, treatment patterns, nutritional status, outcomes, and comorbidity. Dig Dis Sci 2012;57:2408-2415.

45. Johnson SL, Bartels CM, Palta M, Thorpe CT, Weiss JM, Smith MA. Biological and steroid use in relationship to quality measures in older patients with inflammatory bowel disease: a US Medicare cohort study. BMJ Open 2015;5:e008597. doi: 10.1136/bmjopen-2015-008597.

46. Lichtenstein GR, Sands BE, Pazianas M. Prevention and treatment of osteoporosis in inflammatory bowel disease. Inflamm Bowel Dis 2006;12:797-813.

47. Tilg H, Moschen AR, Kaser A, Pines A, Dotan I. Gut, inflammation and osteoporosis: basic and clinical concepts. Gut 2008;57:684-694.

48. Hazlewood GS, Rezaie A, Borman M, et al. Comparative effectiveness of immunosuppressants and biologics for inducing and maintaining remission in Crohn's disease: a network metaanalysis. Gastroenterology 2015;148:344-354.
49. Matsumoto S, Miyatani H, Yoshida Y. Ulcerative colitis: comparison between elderly and young adult patients and between elderly patients with late-onset and long-standing disease. Dig Dis Sci 2013;58:1306-1312.

50. Beaugerie L, Brousse N, Bouvier AM, et al. Lymphoproliferative disorders in patients receiving thiopurines for inflammatory bowel disease: a prospective observational cohort study. Lancet 2009;374:1617-1625.

51. Toruner M, Loftus EV Jr, Harmsen WS, et al. Risk factors for opportunistic infections in patients with inflammatory bowel disease. Gastroenterology 2008;134:929-936.

52. Khan N, Abbas AM, Lichtenstein GR, Loftus EV Jr, Bazzano LA. Risk of lymphoma in patients with ulcerative colitis treated with thiopurines: a nationwide retrospective cohort study. Gastroenterology 2013;145:1007-1015.

53. Peyrin-Biroulet L, Khosrotehrani K, Carrat F, et al. Increased risk for nonmelanoma skin cancers in patients who receive thiopurines for inflammatory bowel disease. Gastroenterology 2011;141:1621-1628.

54. Abbas AM, Almukhtar RM, Loftus EV Jr, Lichtenstein GR, Khan $\mathrm{N}$. Risk of melanoma and non-melanoma skin cancer in ulcerative colitis patients treated with thiopurines: a nationwide retrospective cohort. Am J Gastroenterol 2014;109:1781-1793.

55. Lobatón T, Ferrante M, Rutgeerts P, Ballet V, Van Assche G, Vermeire S. Efficacy and safety of anti-TNF therapy in elderly patients with inflammatory bowel disease. Aliment Pharmacol Ther 2015;42:441-451.

56. Cottone M, Kohn A, Daperno M, et al. Advanced age is an independent risk factor for severe infections and mortality in patients given anti-tumor necrosis factor therapy for inflammatory bowel disease. Clin Gastroenterol Hepatol 2011;9:30-35.

57. Desai A, Zator ZA, de Silva $P$, et al. Older age is associated with higher rate of discontinuation of anti-TNF therapy in patients with inflammatory bowel disease. Inflamm Bowel Dis 2013;19:309-315.

58. Colombel JF, Loftus EV Jr, Tremaine WJ, et al. The safety profile of infliximab in patients with Crohn's disease: the Mayo clinic experience in 500 patients. Gastroenterology 2004;126:19-31.

59. Fidder H, Schnitzler F, Ferrante M, et al. Long-term safety of infliximab for the treatment of inflammatory bowel disease: a single-centre cohort study. Gut 2009;58:501-508.

60. Yajnik V, Khan N, Dubinsky M, et al. Efficacy and safety of vedolizumab in ulcerative colitis and Crohn's disease patients stratified by age. Adv Ther 2017;34:542-559.

61. Navaneethan U, Edminister T, Zhu X, Kommaraju K, Glover S. Vedolizumab is safe and effective in elderly patients with inflammatory bowel disease. Inflamm Bowel Dis 2017;23:E17. doi: 10.1097/MIB.0000000000001071. 
62. Frauman AG. An overview of the adverse reactions to adrenal corticosteroids. Adverse Drug React Toxicol Rev 1996;15:203206.

63. Bernheim O, Colombel JF, Ullman TA, Laharie D, Beaugerie $\mathrm{L}$, Itzkowitz SH. The management of immunosuppression in patients with inflammatory bowel disease and cancer. Gut 2013;62:1523-1528.

64. Qato DM, Alexander GC, Conti RM, Johnson M, Schumm P, Lindau ST. Use of prescription and over-the-counter medications and dietary supplements among older adults in the United States. JAMA 2008;300:2867-2878.

65. Parian A, Ha CY. Older age and steroid use are associated with increasing polypharmacy and potential medication interactions among patients with inflammatory bowel disease. Inflamm Bowel Dis 2015;21:1392-1400.

66. Ananthakrishnan AN, McGinley EL, Binion DG. Inflammatory bowel disease in the elderly is associated with worse outcomes: a national study of hospitalizations. Inflamm Bowel Dis 2009;15:182-189.

67. Limdi JK, Vasant DH. Anorectal dysfunction in distal ulcerative colitis: challenges and opportunities for topical therapy. J Crohns Colitis 2016;10:503.

68. Shung DL, Abraham B, Sellin J, Hou JK. Medical and surgical complications of inflammatory bowel disease in the elderly: a systematic review. Dig Dis Sci 2015;60:1132-1140.

69. Almogy G, Sachar DB, Bodian CA, Greenstein AJ. Surgery for ulcerative colitis in elderly persons: changes in indications for surgery and outcome over time. Arch Surg 2001;136:1396-1400.

70. Longo WE, Virgo KS, Bahadursingh AN, Johnson FE. Patterns of disease and surgical treatment among United States veterans more than 50 years of age with ulcerative colitis. Am J Surg 2003;186:514-518.

71. Bollegala N, Jackson TD, Nguyen GC. Increased postoperative mortality and complications among elderly patients with inflammatory bowel diseases: an analysis of the National Surgical Quality Improvement Program Cohort. Clin Gastroenterol Hepatol 2016;14:1274-1281.

72. Bewtra M, Newcomb CW, Wu Q, et al. Mortality associated with medical therapy versus elective colectomy in ulcerative colitis: a cohort study. Ann Intern Med 2015;163:262-270.

73. Ross H, Steele SR, Varma M, et al. Practice parameters for the surgical treatment of ulcerative colitis. Dis Colon Rectum 2014;57:5-22.

74. Church JM. Functional outcome and quality of life in an elderly patient with an ileal pouch-anal anastomosis: a 10-year follow up. Aust N Z J Surg 2000;70:906-907.
75. Delaney CP, Dadvand B, Remzi FH, Church JM, Fazio VW. Functional outcome, quality of life, and complications after ileal pouch-anal anastomosis in selected septuagenarians. Dis Colon Rectum 2002;45:890-894.

76. Ekbom A, Helmick C, Zack M, Adami HO. Ulcerative colitis and colorectal cancer: a population-based study. N Engl J Med 1990;323:1228-1233.

77. Sugita A, Sachar DB, Bodian C, Ribeiro MB, Aufses AH Jr, Greenstein AJ. Colorectal cancer in ulcerative colitis: influence of anatomical extent and age at onset on colitis-cancer interval. Gut 1991;32:167-169.

78. Shaukat A, Virnig DJ, Salfiti NI, Howard DH, Sitaraman SV, Liff JM. Is inflammatory bowel disease an important risk factor among older persons with colorectal cancer in the United States? A population-based case-control study. Dig Dis Sci 2011;56:2378-2383.

79. Navaneethan U, Parasa S, Venkatesh PG, Trikudanathan G, Shen B. Prevalence and risk factors for colonic perforation during colonoscopy in hospitalized inflammatory bowel disease patients. J Crohns Colitis 2011;5:189-195.

80. Laine L, Kaltenbach T, Barkun A, et al. SCENIC international consensus statement on surveillance and management of dysplasia in inflammatory bowel disease. Gastroenterology 2015;148:639-651.

81. Kandiel A, Fraser AG, Korelitz BI, Brensinger C, Lewis JD. Increased risk of lymphoma among inflammatory bowel disease patients treated with azathioprine and 6-mercaptopurine. Gut 2005;54:1121-1125.

82. Kotlyar DS, Lewis JD, Beaugerie L, et al. Risk of lymphoma in patients with inflammatory bowel disease treated with azathioprine and 6-mercaptopurine: a meta-analysis. Clin Gastroenterol Hepatol 2015;13:847-858.

83. Siegel CA, Marden SM, Persing SM, Larson RJ, Sands BE. Risk of lymphoma associated with combination anti-tumor necrosis factor and immunomodulatory therapy for the treatment of Crohn's disease: a meta-analysis. Clin Gastroenterol Hepatol 2009;7:874-881.

84. Beigel F, Steinborn A, Schnitzler F, et al. Risk of malignancies in patients with inflammatory bowel disease treated with thiopurines or anti-TNF alpha antibodies. Pharmacoepidemiol Drug Saf 2014;23:735-744.

85. Lakatos PL, Lovasz BD, David G, et al. The risk of lymphoma and immunomodulators in patients with inflammatory bowel diseases: results from a population-based cohort in Eastern Europe. J Crohns Colitis 2013;7:385-391.

86. Afif W, Sandborn WJ, Faubion WA, et al. Risk factors for lymphoma in patients with inflammatory bowel disease: a casecontrol study. Inflamm Bowel Dis 2013;19:1384-1389. 
87. Long MD, Herfarth HH, Pipkin CA, Porter CQ, Sandler RS, Kappelman MD. Increased risk for non-melanoma skin cancer in patients with inflammatory bowel disease. Clin Gastroenterol Hepatol 2010;8:268-274.

88. Armstrong RG, West J, Card TR. Risk of cancer in inflammatory bowel disease treated with azathioprine: a UK populationbased case-control study. Am J Gastroenterol 2010;105:16041609.

89. Rahier JF, Magro F, Abreu C, et al. Second European evidencebased consensus on the prevention, diagnosis and management of opportunistic infections in inflammatory bowel disease. J Crohns Colitis 2014;8:443-468.
90. Kim HH, Kim YS, Han DS, et al. Clinical differences in Clostridium difficile infection based on age: a multicenter study. Scand J Infect Dis 2014;46:46-51.

91. Farraye FA, Melmed GY, Lichtenstein GR, Kane SV. ACG clinical guideline: preventive care in inflammatory bowel disease. Am J Gastroenterol 2017;112:241-258.

92. Wasan SK, Baker SE, Skolnik PR, Farraye FA. A practical guide to vaccinating the inflammatory bowel disease patient. Am J Gastroenterol 2010;105:1231-1238. 